\title{
Reduction of carbon dioxide emission through the sorption in situ using a fluidised bed reactor
}

\author{
${ }^{1 A}$ Witold Żukowski, ${ }^{1}$ Sylwia Englot, ${ }^{1}$ Jerzy Baron, ${ }^{2}$ Stanisław Kandefer, ${ }^{2}$ Małgorzata Olek \\ Cracow University of Technology, ul. Warszawska 24, 31-155 Kraków, Poland, \\ ${ }^{A}$ corresponding author: *pczukows@pk.edu.pl \\ ${ }^{1}$ Faculty of Chemical Engineering and Technology; ${ }^{2}$ Faculty of Environmental Engineering
}

The paper discusses the possibility of using the reversible reaction $\mathrm{CaCO}_{3} \leftrightarrow \mathrm{CaO}+\mathrm{CO}_{2}$ for the cyclic capture and release of $\mathrm{CO}_{2}$ directly inside a fluidised bed combustor. This could lead to the lowering of $\mathrm{CO}_{2}$ emissions into the atmosphere, as part of an effort to mitigate the greenhouse effect associated with the rising atmospheric $\mathrm{CO}_{2}$ concentrations resulting from obtaining energy from burning fossil fuels.

An enrichment coefficient $\mathrm{E}$ has been introduced and defined as a measure of the production of $\mathrm{CO}_{2}$ (on calcining $\mathrm{CaCO}_{3}$ ) or its removal (on carbonation of $\mathrm{CaO}$ ) with respect to the level associated with fuel combustion alone. The observations made on the effect of introducing an additional external stream of $\mathrm{CO}_{2}$ on the efficiency of the chemical capture process have been described. Through an appropriate control of the temperature inside the reactor it is possible to change the value of $\mathrm{E}$ over the range $[-0.8 ; 0.8]$. This implies that up to about $80 \%$ of the $\mathrm{CO}_{2}$ derived from the fuel can be temporarily retained within the bed and released later, at a higher concentration. The proposed method of burning fuel in a chemically active fluidised bed could be an available method leading to $\mathrm{CO}_{2}$ isolation from the flue gases and leading to its eventual sequestration.

Keywords: fluidisation, combustion, $\mathrm{CO}_{2}$ sequestration.

\section{INTRODUCTION}

Carbon dioxide is a greenhouse gas contributing to keeping some of the solar heat radiation within Earth's atmosphere. However, its presence in the atmosphere is crucial both for plants to perform photosynthesis and to sustain the right temperature on the surface. The problem is its growing concentration in the atmosphere, which results from increasing the combustion of fossil fuels.

One possibility of decreasing $\mathrm{CO}_{2}$ emission when producing is carbon capture and storage. It is the process of capturing $\mathrm{CO}_{2}$ from flue gases at large point sources and storing it in geologic formations, in oceans or using the gas in various industries rather than emitting it into the atmosphere. However, there is still no economically effective method of eliminating carbon dioxide from the exhausts. The solution proposed in this paper is based on using a fluidised bed reactor to burn fossil fuels. If the reactor's bed is a layer of calcium oxide, then by changing the bed's temperature accordingly, it is possible to conduct the sorption (or desorption) of carbon dioxide generated by combustion in situ. The method of burning fossil fuels via fluidised bed combustion enables capturing carbon dioxide when burning the fuel rather than conducting a separate process ie. separating the gas from flue gases.

\section{EXPERIMENTAL}

A fluidised bed reactor with a bubbling bed can be used to combust the fuels which are either solid, liquid or gaseous ${ }^{1-17}$. The material used in the bed can be chemically inert (quartz sand), it can have catalyst properties or be chemically active.

Adding calcium carbonate to the fluidised bed to achieve desulphurisation during the combustion of bituminous coal may serve as an example of the latter. The process of calcining calcium carbonate results in enriching the fluidised bed with the grains composed of calcium oxide. Calcination is a reversible process, which means that depending on the temperature, cal- cium carbonate can dissolute into calcium oxide and carbon dioxide or be created from calcium oxide via the absorption of carbon dioxide. The thermal dissolution equilibrium equation is in the form of:

$\mathrm{CaCO}_{3} \leftrightarrow \mathrm{CO}_{2}+\mathrm{CaO}$

Molecular pressure of carbon dioxide $\left(\mathrm{P}_{\mathrm{CO} 2}\right)$ depends on temperature and can be defined by the following dependence ${ }^{18}$. $P_{\mathrm{CO}_{2}}=2.15 \cdot 10^{7} \cdot e^{\frac{-I}{R T}}$

where $I$ stands for calcium carbonate decomposition enthalpy.

The analysis of the dependence of balanced carbon dioxide - calcium carbonate concentration in flue gases on temperature (Fig.1) shows that by applying calcium oxide as the fluidised bed and controlling the temperature enables, under certain conditions, carbon dioxide absorption within the reactor's bed. The maximum temperature in which the sorption takes place depends on carbon dioxide concentration inside the reactor. If the $\mathrm{CO}_{2}$ concentration resulting from combustion is at the level

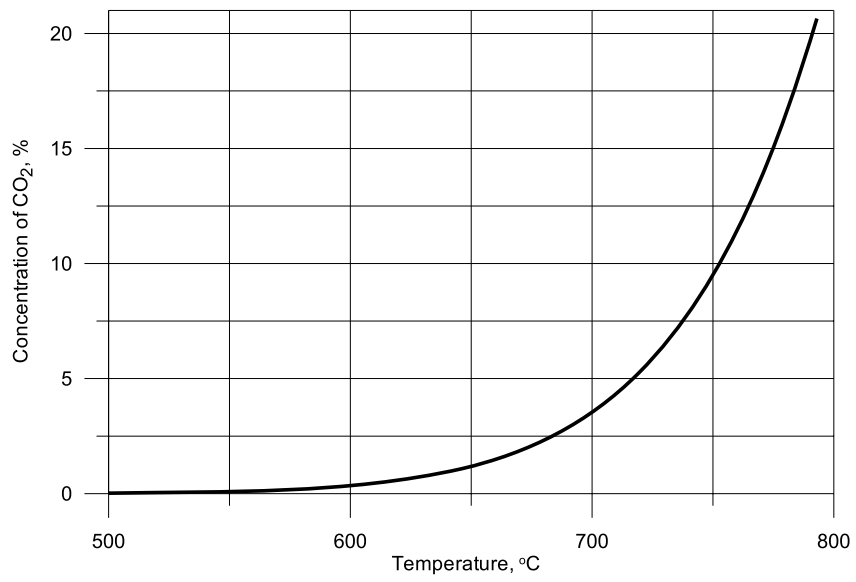

Figure 1. Relation between the concentration of $\mathrm{CO}_{2}$ in flue gases being in equilibrium with calcium to temperature, total pressure101325 $\mathrm{Pa}$. 
of $5-15 \%$ then, according to the dependence (2) the temperature required to conduct sorption is in the range $716-744^{\circ} \mathrm{C}$.

Carbon dioxide sorption is further aided by the presence of $\mathrm{CO}_{2}$ in the gases that are fed into the reactor. In view of thermodynamics, the presence of additional carbon dioxide raises the maximum allowable temperature for the sorption to take place and regarding kinetics - raises the chemical reaction's effectiveness by prolonging the contact between the reagents and by increasing the $\mathrm{CO}_{2}$ concentration in the fluidised bed. Such case is possible when the combusted gas contains both the combustible substances and carbon dioxide (for instance, biogas or the gas produced through the gasification of bituminous coal).

In order to establish the actual contribution of $\mathrm{CO}_{2}$ sorption it is essential to know the flue gases' composition (oxygen, carbon dioxide, carbon oxide, molecular nitrogen) and then, using the stoichiometric coefficients of the combustion equation and calcination processes, establish the individual contribution of each reaction in the process. To do so, the following dependences that allow calculating the flue gases' molar flow rate $\left(\mathrm{n}_{\mathrm{sp}}\right)$, the air coefficient and the enrichment coefficient $(\mathrm{E})^{\mathbf{1 9}}$, were deducted:

$$
\begin{aligned}
& n_{f l}=n_{C O 2, d}+0.126 \cdot a \cdot n_{o x}+0.209 \cdot(1-a) \cdot n_{o x}+0.791 \cdot n_{o x} \\
& a=1-\frac{3.7847 \cdot y_{O 2, f l}^{\prime}}{1-y_{O 2, f l}^{\prime}-y_{C O 2, f l}^{\prime}}
\end{aligned}
$$

$E=\frac{n_{C O 2, d}}{n_{C O 2, p}}=\frac{\frac{79.1}{1-y_{O 2, f l}^{\prime}-y_{C O 2, f l}^{\prime}}+8.36 \cdot a-100}{12.6 \cdot a}$

The dependencies above were deducted assuming that carbon dioxide is not added to the stream of materials and the numbers 8.36 and 12.6 in the equation (5) result from the stoichiometric coefficients of combustion reaction for a given type of fuel - in this case propane. Adding $\mathrm{CO}_{2}$ to the substrates' stream results in introducing another factor:

$Q_{\mathrm{CO} 2}=\frac{n_{\mathrm{CO} 2, \text { add }}}{n_{o x}}$

Considering $Q_{\mathrm{CO} 2}$, the flue gases' amount equation has the following form:

$n_{f l}=n_{C O 2, d}+0.126 \cdot a \cdot n_{o x}+0.209 \cdot(1-a) \cdot n_{o x}$

$+0.791 \cdot n_{o x}+Q_{\mathrm{CO} 2} \cdot n_{o x}$

The dependency linking the values of the E coefficient with the flue gases' composition has the following form:

$E^{\prime}=\frac{n_{C O 2, d}}{n_{C O 2, p}}=\frac{\frac{79.1}{1-y_{O 2, s p}^{\prime}-y_{C O 2, f l}^{\prime}}+8.36 \cdot a-100 \cdot\left(1+Q_{C O 2}\right)}{12.6 \cdot a}$

As it was demonstrated previously ${ }^{\mathbf{1 8}}$, controlling the bed's temperature allows cyclic carbon dioxide adsorption from the flue gases' stream. Further experiments were focused on analyzing the effectiveness of sorption and calcination when adding an outside influx of carbon dioxide into the bed.

The experiments were conducted in a reactor of which the sidewall is a quartz pipe (96 $\mathrm{mm}$ in diameter, $3 \mathrm{~mm}$ wall thickness, $500 \mathrm{~mm}$ height). The reactor was closed from underneath by the mixing chamber. A mixture of air, propane and carbon dioxide is pumped into the mixing chamber. The fluidised bed reactor layout is shown in Figure 2. A layer of carbide

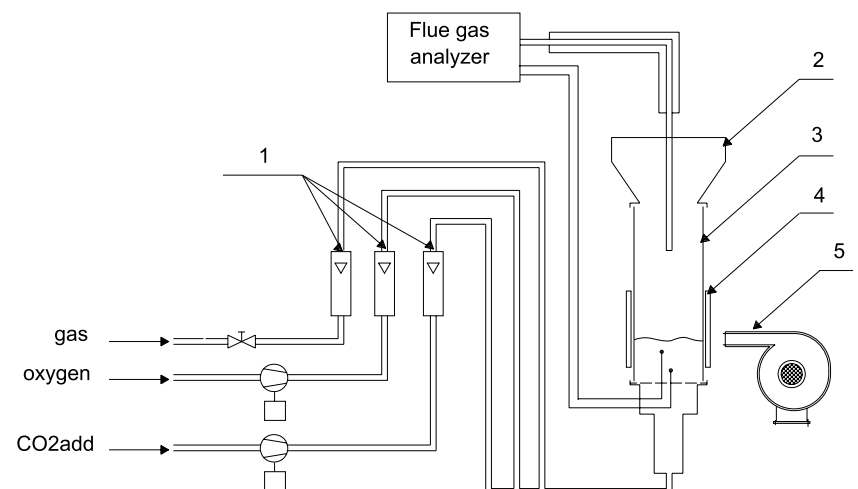

Figure 2. The bubbling fluidised bed and associated equipment (schematic): 1 - rotameters; 2 - metal cover; 3 - freeboard, 4 - movable radiation shield; 5 fan.

residue with grains' diameter ranging from $0.75-1.2 \mathrm{~mm}$ was used as the fluidised bed. The parameters changed during the burning process were the volume stream of propane and air and the temperature of the solid layer of the bed. The burning process was conducted while periodically changing the bed's temperature in the range of $650-900^{\circ} \mathrm{C}$ according to a previously fixed schedule.

The concentration of oxygen, carbon oxides, nitrous oxide and sulphur dioxide in the flue gases was measured using an MRU Vario Plus flue gases' analyser and recorded at $1 \mathrm{~s}^{-1}$ intervals. The gases were sampled at the height of $200 \mathrm{~mm}$ above the bed's surface. The experiment was conducted while changing the bed's temperature to below and above the dissolution temperature of the calcite. Changing the temperature was done by accordingly manipulating the heat reception from the reactor. The experiment was separated into parts witch include both adsorption and desorption of carbon dioxide. The results are presented by Figure 3.

The experiment began by rapidly heating up the bed above the calcite's dissolution temperature. Thus, the bed was prepared to the proper part of the experiment. The carbon dioxide sorption stage was initiated by cooling the reactor's bed to below the temperature after the initial heating and was sustained for a certain period of time. During this stage of the experiment, carbon dioxide concentration was closing (fig. 3a) or reaching the gas' concentration in the input stream (fig. 3b). This means that the rate of carbon dioxide sorption was close or equal to the amount of carbon dioxide produced during the combustion. During the sorption, the concentration of carbon oxide in the gases leaving the bed increases, however, a larger device with a larger volume above the bed should provide the combustion of this gas. In the next stage of the experiment, the heat reception from the reactor was decreased, thus initiating the period of desorption.

$\mathrm{CaCO}_{3}$ dissolution is an endothermic process so it halts the temperature increase which can be observed after desorption has been concluded. During carbon dioxide desorption, its concentration reaches the value in the range of $15-22 \%$. Under the same conditions when burning propane in a sand bed without adding carbon dioxide, the carbon dioxide concentration in the flue gases falls in the range of $9-12 \%$.

The time in which sorption and desorption take place results from a fixed schedule of changing the bed's temperature and can be applied to both reactions separately. It is possible to create an asymmetric development of $\mathrm{CO}_{2}$ concentration changes in exhausts which require a much longer period of $\mathrm{CO}_{2}$ sorption 
a)

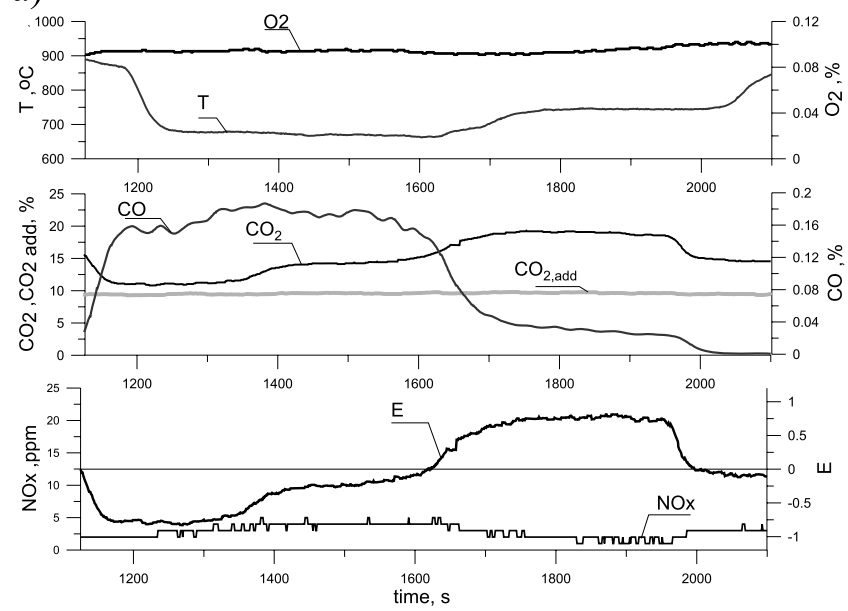

b)
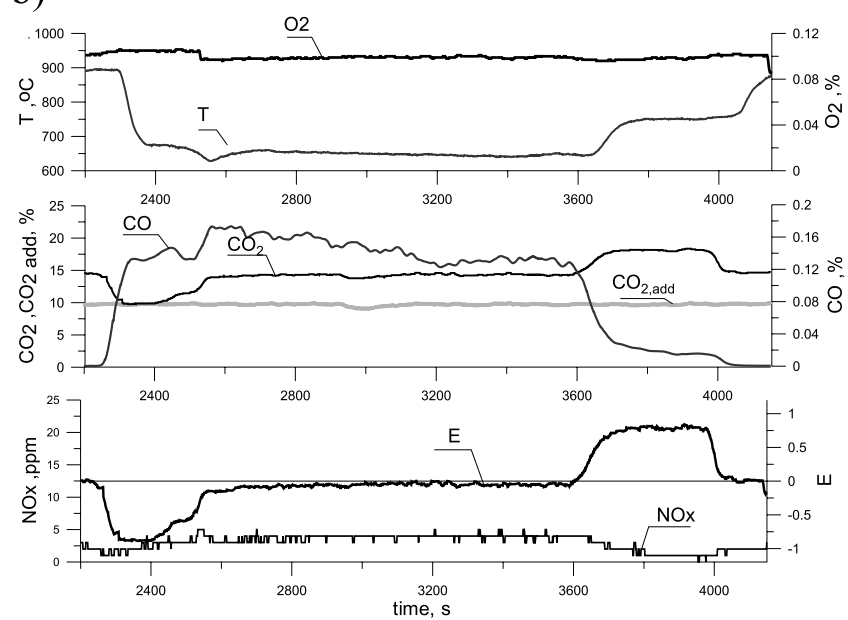

c)
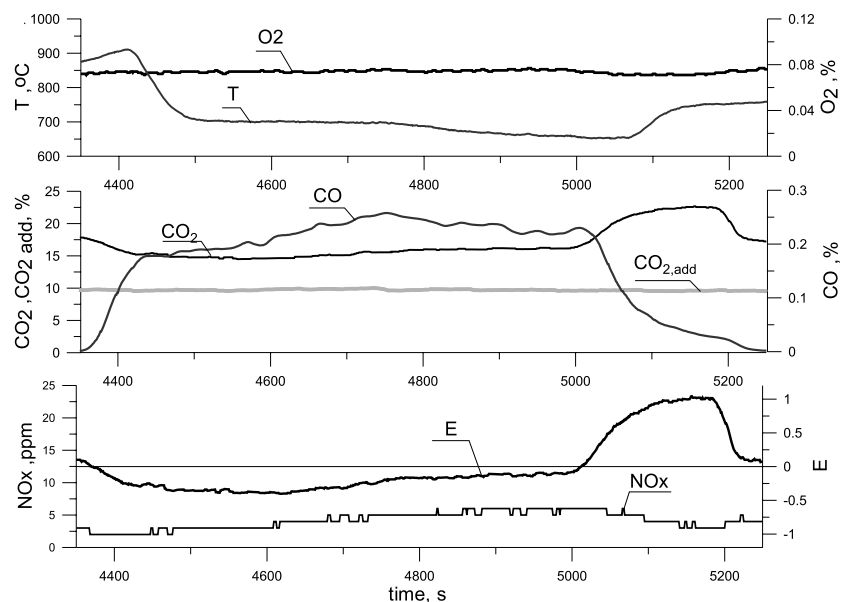

Figure 3. Flue gas composition during the capture and release of $\mathrm{CO}_{2}$

than the time required for it to be removed from the fluidized bed (fig. 3c).

It is worth noting that high levels of nitrous oxides were observed only in the first phase of the experiment (during the bed's preparation). In the proper part of the experiment the concentration of nitrous oxides was never above $6 \mathrm{ppm}$.

\section{CONCLUSIONS}

Combusting a gaseous fuels inside a reactor with a chemically active fluidised bed has proven to be a low-emission process. It was also affirmed that nitrous oxides concentration is up to 3 times lower than burning propane in similar conditions but when using a sand bed. These numbers are not higher than a few ppm's.

Adsorption - desorption cycles which were applied in the experiment allow a substantial decrease of $\mathrm{CO}_{2}$ concentration in the flue gases due to its sorption when the bed's temperature is lower. In relative numbers, it means a decrease in $\mathrm{CO}_{2}$ concentration in the flue gases, due to the combustion's stoichiometry and applying the added $\mathrm{CO}_{2}$ and air excess coefficient, from $14 \%$ to less than $10 \%$. During adsorption, the value of the E coefficient reached a minimal value between -0.8 and -1 . Considering the $\mathrm{E}$ coefficient's definition, this means that the chemically active fluidised bed was able to bond carbon dioxide inside the reactor at the rate close to the rate in which carbon dioxide was produced in the burning process. Such a rate was made possible by intensifying the sorption process by adding carbon dioxide into the substrates' stream. In practice, such a case is possible when burning biogas or a mixture of gases produced in the process of carbonization or fuel gasification.

When the fluidised layer temperature was higher than the temperature of $\mathrm{CaCO}_{3}$ dissolution, we can observe $\mathrm{CO}_{2}$ desorption. This contributed to the increase of $\mathrm{CO}_{2}$ concentration in flue gases from 14 to $22 \%$. The temperature of the bed was kept at this level in order to limit the rate of carbon dioxide desorption from the bed. Such actions were motivated by the need of limiting the carbon dioxide concentration below $25 \%$ (the highest value that can be measured by the applied flue gases analyzer). Performing further tests showed the possibility of reaching higher $\mathrm{CO}_{2}$ concentration levels - above $25 \%$.

\section{NOMENCLATURE}

$P_{\mathrm{CO} 2}$ - partial pressure of carbon dioxide, bar

I - calcium carbonate decomposition enthalpy, $\mathrm{kJ} /$ mol

$R \quad$ - universal gas constant, $\mathrm{J} /\left(\mathrm{mol}^{*} \mathrm{~K}\right)$

$T$ - temperature of equilibrium for calcination, $\mathrm{K}$

a - air coefficient of the combustion system

$n_{f l} \quad$ - flue gases' molar flow rate, $\mathrm{mol} / \mathrm{s}$

$n_{\mathrm{CO} 2, d}-\mathrm{CO}_{2}$ molar flow rate, arise as a result dissolution of $\mathrm{CaCO}_{3}, \mathrm{~mol} / \mathrm{s}$

$n_{\mathrm{CO} 2, \mathrm{p}}-\mathrm{CO}_{2}$ molar flow rate, arise as a result of burning propane, $\mathrm{mol} / \mathrm{s}$

$n_{\mathrm{CO}, \text { add }}-$ extra $\mathrm{CO}_{2}$ molar flow rate, added to reactor, $\mathrm{mol} / \mathrm{s}$

$n_{o x}$ - Air molar flow rate added to reactor, $\mathrm{mol} / \mathrm{s}$

$y_{\mathrm{CO}, f l}^{\prime}$ - mole fraction of $\mathrm{CO}_{2}$ in flue gases in conditions of complete combustion

$y_{O 2, f l}^{\prime}$ - mole fraction of $\mathrm{O}_{2}$ in flue gases in conditions of complete combustion

$Q_{\mathrm{CO} 2}$ - molar proportion of added $\mathrm{CO}_{2}$ to air

$E$ - enrichment coefficient without addition of extra $\mathrm{CO}_{2}$ to fluidised bed

$E^{\prime} \quad$ - enrichment coefficient with addition of extra $\mathrm{CO}_{2}$ to fluidised bed

\section{LITERATURE CITED}

1. Avedesian, M.M. \& Davidson, J.F. (1973). Combustion of carbon particles in a fluidised bed. Trans. Inst. Chem. Eng. $51, \quad 121-131$

2. Stubington, J.F. \& Davidson, J.F. (1981). Gas-phase combustion in fluidized beds. AIChE Journal. 27, $59-65$

3. Dennis, J., Hayhurst, A.N. \& Mackley, I.G. (1982). The ignition and combustion of propane/air mixtures in a fluid- 
ised bed. In Revelling in Reference: 19th Symposium (Int.) on Combustion 8-13 August 1982 (pp. 1205 - 1212). Haifa, Israel: The Combustion Institute, Pittsburgh

4. Hayhurst, A.N. \& Tucker, R.F. (1990). The combustion of carbon monoxide in a two-zone fluidized bed. Combust. Flame. 79, 175 - 189 DOI: 10.1016/0010-2180(90)90042-P

5. Hayhurst, A.N. (1991). Does carbon monoxide burn inside a fluidized bed? A new model for the combustion of coal char particles in fluidized beds. Combust. Flame. 85, 155 $-168$

6. Hesketh, R.P. \& Davidson, J.F. (1991). Combustion of methane and propane in an incipiently fluidized bed. Combust. Flame. 85, 449 - 467

7. Kandefer, S. \& Pilawska, M. (1995). Fluidised Bed Combustion of Gaseous Fuels. In Revelling in Reference: 3rd International Conference on Technologies and Combustion for a Clean Environment 3-6 July 1995 (pp. 29.4.2228). Lisbon, Portugal: Technical University of Lisbon.

8. Stubington, J.F. \& Clough, S.J. (1997). The combustion rate of volatiles in a fluidized bed combustor. In Revelling in Reference: $14^{\text {th }}$ International Conference on Fluidized Bed Conmbustion 11 - 14 May 1997 (pp.1111 - 1122, Vol. 2.). Vancouver, Canada: ASME, New York

9. Żukowski, W. (2002) The pressure pulses generated by the combustion of natural gas in bubbling fluidized beds. Combust. Flame. 130, 15 - 26 DOI: 10.1016/S00102180(02)00357-7

10. Baron, J., Bulewicz, E.M., Kandefer, S., Pilawska, M. \& Żukowski, W. (2002). Combustion of hydrocarbon fuels in a bubbling fluidized bed. Combust. Flame. 128, 410 - 421 DOI: $10.1016 /$ S0010-2180(01)00359-5

11. Zukowski, W. (2003). A simple model for explosive combustion of premixed natural gas with air in a bubbling fluidized bed of inert Combust. Flame. 134, 399 - 409 DOI: 10.1016/S0010-2180(03)00139-1

12. Pilawska, M., Baron, J. \& Żukowski, W. (2003). Combustion of Aromatics and Esters in an Atmospheric Bub- bling FBC in Comparison with that of Natural Gas. In Revelling in Reference: $7^{\text {th }}$ International Conference on Technologies and Combustion for a Clean Environment 7 10 July 2003 (pp 36.3). Lisbon, Portugal: Technical University of Lisbon.

13. Bulewicz, E.M., Żukowski, W., Kandefer, S. \& Pilawska, M., (2003). Flame flashes when bubbles explode during the combustion of gaseous mixtures in a bubbling fluidized bed. Combust. Flame. 132, 319 - 327 DOI: 10.1016/S00102180(02)00466-2

14. Żukowski, W. (2004). Combustion of Gaseous Fuels in a Fluidised Bed of Inert Particles (in Polish). Cracow, Poland: Cracow University of Technology

15. Żukowski, W. (2005). Methane and Ethane Combustion in an Inert Fluidized Bed. In Revelling in Reference: 18th International Conference on Fluidized Bed Combustion 22 - 25 May 2005 (paper FBC2005-78100). Toronto, Canada: ASME, New York

16. Baron, J., Bulewicz, E.M., Kandefer, S., Pilawska, M. \& Żukowski, W. (2006). A simple physicochemical view of bubbling. In Revelling in Reference: 19th International Conference on Fluidized Bed Combustion 21 - 24 May 2006 (Paper 43C). Vienna, Austria: Vienna University of Technology

17. Baron, J., Bulewicz, E.M., Kandefer, S., Pilawska, M., Żukowski, W. \& Hayhurst, A.N. (2006). The combustion of polymer pellets in a bubbling fluidised bed. Fuel. 85, 2494 2508 DOI: 10.1016/j.fuel.2006.05.004

18. Żukowski, W., Baron, J., Błaszczyk-Pasteczka, A., Kandefer, S. \& Olek, M. (2008). Effects of burning propane in inert and chemically active fluidized beds. Przem. Chem. $87(2), \quad 214-218$

19. Bes, A. (2006). Dynamic Process Simulation of Limestone Calcination in Normal Shaft Kilns. Unpublished doctoral dissertation, Otto-von-Guericke Magdeburg University, Magdeburg, German 